\title{
First report of hepatic hematoma after presumed Bothrops envenomation
}

\author{
Fernanda Cristina Cunha ${ }^{[1]}$, Maike Heerdt ${ }^{[1]}$, Pasesa Pascuala Quispe Torrez ${ }^{[2]}$, \\ Francisco Oscar de Siqueira França ${ }^{[2],[3],}$ Graziela Zibetti Dal Molin ${ }^{[1],}$ \\ Rúbia Battisti ${ }^{[1]}$ and Marlene Zannin ${ }^{[1],[4]}$
}

[1]. Centro de Informações Toxicológicas, Hospital Universitário, Universidade Federal de Santa Catarina, Florianópolis, Santa Catarina, Brazil. [2]. Núcleo de Medicina Tropical (Santarém, Pará), Departamento de Doenças Infecciosas e Parasitárias, Universidade de São Paulo, São Paulo, Brazil. [3]. Departamento de Doenças Infecciosas e Parasitárias, Faculdade de Medicina, Universidade de São Paulo, São Paulo, Brazil. [4]. Departamento de Patologia, Universidade Federal de Santa Catarina, Florianópolis, Santa Catarina, Brazil.

\begin{abstract}
In Latin America, Bothrops envenomation is responsible for the majority of accidents caused by venomous snakes. Patients usually present local edema, bleeding and coagulopathy. Visceral hemorrhage is extremely rare and considered a challenge for diagnosis and management. We report the first case of hepatic hematoma owing to the bothropic envenomation in a 66-yearold man who was bitten in the left leg. He presented local edema, coagulopathy, and acute kidney injury. Radiological findings suggested hepatic hematoma, with a volume of almost 3 liters. The hepatic hematoma was gradually absorbed without the need for surgical intervention with complete resolution in 8 months.
\end{abstract}

Keywords: Snakebite. Bothrops envenomation. Hepatic hematoma.

\section{INTRODUCTION}

Snakebites are a significant public health problem especially in the tropical countries of Latin America, Africa, and Asia. It is estimated that 5.4 million bites, more than 2,500,000 envenomations, and about 125,000 deaths will occur annually ${ }^{(1)}$. According to the Ministry of Health, 24,359 accidents due to venomous snakes occurred in Brazil in 2104, and 71.5\% were caused by Bothrops snakes ${ }^{(2)}$.

Similar to accidents caused by many genuses of the Viperidae family globally, Bothrops snake bites frequently involve local edema, coagulopathy, and hemorrhage. Local complications, such as necrosis, abscesses, compartmental syndrome, and amputation can occur with variable frequency, although systemic complications such as acute kidney injury (AKI), shock, and severe hemorrhage are unusual. Severe bleeding in vital organs, after snake bites, has a poor prognosis with considerable lethality $\left.{ }^{(3)}\right)^{(4)}$.

Systemic hemorrhage is associated with several underlying mechanisms, such as coagulopathy, platelet dysfunction, and microvascular damage caused by snake venom

Corresponding author: Prof. Francisco Oscar de Siqueira França. Depto. de Doenças Infecciosas e Parasitárias/FM/USP. Av. Dr. Enéas de Carvalho Aguiar 470/1 ${ }^{\circ}$ andar/sala 102, Cerqueira César, 05403-000 São Paulo, Brasil.

Phone: 5511 30617018; Mobile: 55 11 9-9645-2764

e-mail: fosfranca@usp.br

Received 27 March 2015

Accepted 12 May 2015 metalloproteinases (SVMPs) ${ }^{(5)(6)(7)(8)}$. Visceral hemorrhage is rarely observed. To the best of our knowledge, this is the first case report of hepatic hematoma after a presumed Bothrops bite.

\section{CASE REPORT}

In March 2006, a previously healthy 66-year-old man was bitten by a snake in the left leg, in Leal Leoberto. Three hours later, he was admitted to the Bom Jesus Hospital (Ituporanga, State of Santa Catarina). The victim allegedly saw the snake that bit him and identified it as a Bothrops. On physical examination, the patient appeared to be in good condition, ambulated, and demonstrated stable vital signs. Laboratory tests showed abnormal activated partial thromboplastin time (aPTT) and renal function (Table 1). Upon admission, the patient's condition was moderately severe and he received seven vials of antibothropic antivenom intravenously. The patient did not report a history of liver disease or coagulopathy. On the same day, he developed swelling and pain in the left lower limb, skin pallor, abdominal distention, and absence of flatulence.

The next day, the patient began to experience pain in the epigastrium and right upper quadrant radiating to the ipsilateral shoulder. Ultrasonography (USG) findings were suggestive of a hepatic hematoma.

Computed tomography (CT) of the abdomen revealed an extensive hypodense, subcapsular lesion with regular borders, measuring about $21 \times 19 \times 7 \mathrm{~cm}$ and with a volume of $2,793 \mathrm{~cm}^{3}$ (milliliters) in the right hepatic lobe (Figure 1). 
TABLE 1 - Laboratory tests during hospitalization.

\begin{tabular}{|c|c|c|c|c|c|c|c|c|}
\hline \multirow{2}{*}{ Post-envenomation } & \multicolumn{8}{|c|}{ Days } \\
\hline & 1 & 2 & 3 & 4 & 6 & 7 & 14 & 30 \\
\hline Creatinine (mg/dL) & 1.82 & 2.14 & - & 1.68 & - & 1.23 & 1.31 & 0.7 \\
\hline Urea nitrogen (mg/dL) & - & 87 & - & 79 & - & 51 & 64 & 31 \\
\hline Hemoglobin (g/dL) & 15 & - & 10 & 11 & 10 & 10 & 14 & 11 \\
\hline AST & - & - & - & - & 80 & 75 & - & 30 \\
\hline ALT & - & - & - & - & 240 & 180 & - & 55 \\
\hline
\end{tabular}

aPTT: activated partial thromboplastin time: 25-35 seconds; AST: aspartate aminotransferase: 10-40U/L; ALT: alanine aminotransferase: 7-56U/L. Reference ranges: hemoglobin: $12-16 \mathrm{~g} / \mathrm{dL}$; hematocrit: $37-47 \%$; urea: $15-40 \mathrm{mg} / \mathrm{dL}$; creatinine: $0.4-1.3 \mathrm{mg} / \mathrm{dL}$.

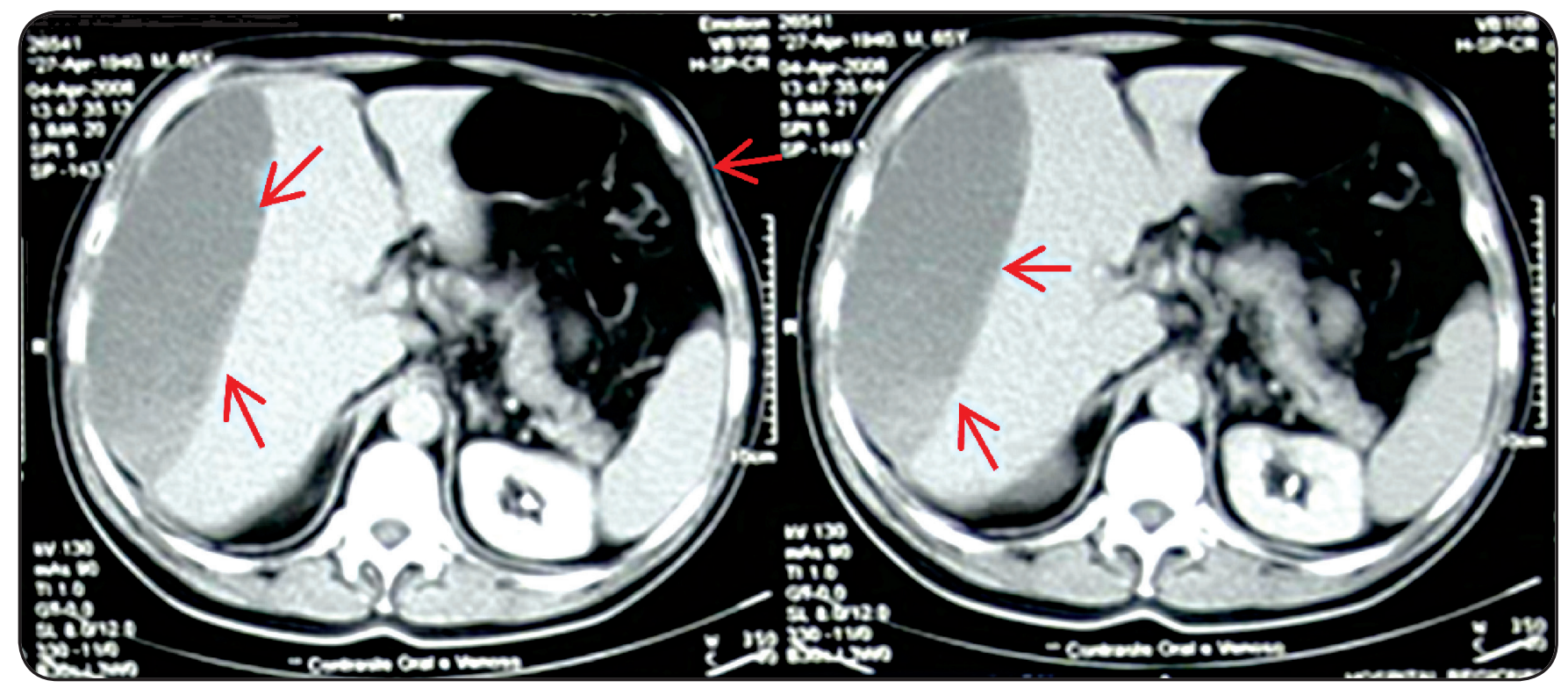

FIGURE 1 - Unenhanced axial computed tomography scan shows a subcapsular hematoma in the perihepatic space (arrows).

The patient remained hemodynamically stable, and expectant management was adopted. On the fifth day after the accident, USG was repeated, and showed a hepatic hematoma with a volume of $930 \mathrm{~cm}^{3}$. On the fifteenth day, another USG was performed that showed a hematoma with a volume of $17 \mathrm{~cm}^{3}$, compatible with progressive spontaneous reabsorption.

Laboratory findings showed progressive improvement during hospitalization, and the patient was discharged 16 days after admission (Table 1). The patient was seen regularly on an outpatient basis. Five months after discharge, a new control USG showed a hematoma with volume of $6.3 \mathrm{~cm}^{3}$. Eight months after the accident there was no more evidence of the hepatic hematoma.

\section{DIscussion}

Many Viperidae snakebites, for example, Bothrops genus bites are characterized by progressive inflammatory manifestations at the bite site, consumption coagulopathy, and bleeding. The clinical condition presented by this patient (local edema, coagulopathy, and bleeding) can be attributed only to Bothrops snake bite, usually observed in the State of Santa Catarina (Brazil), where the patient was bitten. Snakes of the Lachesis genus are not found in this region, and victims of bites from the South American rattlesnake (Crotalus durissus terrificus) and coral snakes (Micrurus $s p$ ) have neurologic 
manifestations, such as ptosis, diplopia, and paralysis of muscle groups that are incompatible with those of Bothrops envenomation. The patient was treated appropriately and received 7 vials of the specific serum, as recommended by the Brazilian guidelines for cases classified as moderately severe ${ }^{(3)}$ (4) $^{(4)}$

Bothropic accidents can cause bleeding due to several mechanisms, as exemplified by the activities of the coagulation cascade, either directly, through activations of factors X, II, and I (thrombin-like activity), or indirectly, through factor VII activation after endothelial damage caused by SVMPs, platelets abnormalities and disintegrin toxins ${ }^{(5)(6)(7)(8)}$.

The local hemorrhagic manifestations are common and are usually not severe (bruising, gingival bleeding, epistaxis, and microscopic hematuria). Macroscopic hematuria, oliguria, and increased serum creatinine often occurs, mainly in cases of progression to AKI. These are probably the most precocious manifestations of this complication and can be severe, requiring dialysis ${ }^{(9)(10)}$. The patient presented AKI, on the basis of changes in urea and creatinine levels until the fourteenth day of hospitalization.

Hemorrhages in other vital organs, for example, cerebral hemorrhages and bleeding from the gastrointestinal and respiratory tract are even less frequent( ${ }^{(4)(6)(10)(11)}$. Visceral bleeding is even rarer and usually occurs in the abdomen (pancreas, peritoneum, spleen, and liver). Systemic hemorrhage in these organs have poor prognosis, with considerable mortality rates. The intense liver hemorrhage observed in the present case was probably due to several factors, such as consumption coagulopathy, thrombocytopenia, platelet dysfunction, and direct action of hemorrhagins ${ }^{(5)}(10)(11)$.

Diagnostic imaging is essential for the definitive diagnosis and for the adequate clinical management of the liver bleeding. $\mathrm{CT}$ and magnetic resonance imaging are tools that yield more precise information than USG in the characterization of hemorrhagic collection ${ }^{(12)}$.

According to Van der Vlies et al. ${ }^{(12)}$, the progress in imaging techniques has contributed to nonoperative management (NOM), currently considered the treatment of choice for hemodynamically stable patients after blunt injury to solid abdominal organs with hematoma. Angioembolization can be used as an adjunct to NOM and has increased the success rate ${ }^{(12)}$.

Although the patient had extensive hemorrhage collection in the liver, as observed by CT and several USGs (images not displayed), expectant management was maintained, because the patient was hemodynamically stable and the hematoma was gradually absorbed, despite the decreased hemoglobin and hematocrit.

The evolution of hepatic hematoma is variable and the treatment is, essentially, expectant. Surgical intervention is necessary only in cases of hemodynamic instability, progressive pain, and continued expansion of the hematoma ${ }^{(12)}$. A surgical approach could also be necessary if the patient had progressive worsening of coagulation parameters ${ }^{(12)}$. However, in this case, the aPTT remained stable and normalized 2 days after the accident (Table 1).

To our knowledge, this is the third report of liver hemorrhage after a snake bite. In general, we cannot rule out the possibility that the visceral hemorrhagic manifestation after a snake bite may be associated with localized vascular malformation and/or pre-existing disease, such as diabetes mellitus and/or hypertension, which slowly evolve with vasculopathy.
Systemic bleeding is a rare complication of snake bites, with varying severity, but can even cause death. Therefore, we must always evaluate the possibility of this complication caused by snakes whose venom affects hemostasis. Although visceral hemorrhage in the abdomen is rare after snakebites, it is possible that, in situations where the bleeding progresses slowly, it may go unnoticed owing to nonspecific manifestations such as pain and distention of the affected organ.

\section{ACKNOWLEDGMENTS}

We thank the staff of Hospital Bom Jesus, State of Santa Catarina, for their assistance.

\section{CONFLICT OF INTEREST}

The authors declare that there is no conflict of interest.

\section{REFERENCES}

1. Chippaux JP. Snake-bites: appraisal of the global situation. Bull World Health Organ 1998; 76:515-524.

2. Sistema de Informação de Agravos de Notificação (SINAN). (Internet). Brasília: Ministério da Saúde. (Accessed 2015 February 25) Available at http://dtr2004.saude.gov.br/sinanweb/tabnet/ tabnet?sinannet/animaisp/bases/animaisbrn

3. Ministério da Saúde. Fundação Nacional da Saúde. Manual de diagnóstico e tratamento de acidentes por animais peçonhentos. $2^{\text {nd }}$ ed. Brasília: Ministério da Saúde; 2001.

4. Cardoso JL, Fan HW, França FO, Jorge MT, Leite RP, Nishioka AS, et al. Randomized comparative trial of three antivenoms in the treatment of envenoming by lance-headed vipers (Bothrops jararaca) in São Paulo, Brazil. Q J Med 1993; 86:315-325.

5. Yamashita KM, Alves AF, Barbaro KC, Santoro ML. Bothrops jararaca venom metalloproteinases are essential for coagulopathy and increase plasma tissue factor levels during envenomation. PLoS Negl Trop Dis 2014; 8:e2814.

6. White J. Snake venoms and coagulopathy. Toxicon 2005; 45:951-967.

7. Escalante T, Rucavado A, Fox JW, Gutiérrez JM. Key events in microvascular damage induced by snake venom hemorrhagic metalloproteinases. J Proteomics 2011; 74:1781-1794.

8. Kamiguti AS, Rugman FP, Theakston RD, Franca FO, Ishii H, Hay CR, Butantan Institute Antivenom Study Group. The role of venom haemorrhagin in spontaneous bleeding in Bothrops jararaca envenoming. Thromb Haemost 1992; 67:484-488.

9. Sgrignolli LR, Mendes GEF, Carlos CP, Burdmann EA. Acute kidney injury caused by bothrops snake venom. Nephron Clin Pract 2011; 119:131-137.

10. França FOS, Medeiros CR, Málaque CMS, Duarte MR, ChudzinskiTavassi AM, Zannin M, et al. Acidentes por animais peçonhentos. In: Martins MA, Carrilho FJ, Alves VAF, Castilho EA. Clínica Médica. Vol. 7. $1^{\text {st }}$ ed. Barueri: Manole; 2009. p. 553-613.

11. Benvenuti LA, França FO, Barbaro KC, Nunes JR, Cardoso JL. Pulmonary haemorrhage causing rapid death after Bothrops jararacussu snakebite: a case report. Toxicon 2003; 42: 331-334.

12. Van der Vlies CH, Olthof DC, Gaakeer M, Ponsen KJ, van Delden $\mathrm{OM}$, Goslings JC. Changing patterns in diagnostic strategies and the treatment of blunt injury to solid abdominal organs. Int J Emerg Med 2011; 4:1-9. 